\title{
Independence of neutral and adaptive divergence in a low dispersal marine mollusc
}

\author{
Stefano Mariani ${ }^{1,2, *, * *}$, Katja T. C. A. Peijnenburg ${ }^{1,3, * *}$, David Weetman ${ }^{4}$ \\ ${ }^{1}$ School of Biology and Environmental Science, University College Dublin, Science Centre West, Belfield, Dublin 4 , \\ Republic of Ireland \\ ${ }^{2}$ School of Environment \& Life Sciences, Peel Campus, The University of Salford, Greater Manchester M5 4WT, UK \\ ${ }^{3}$ Institute for Biodiversity and Ecosystem Dynamics, Faculty of Science, University of Amsterdam, PO Box 94240, \\ 1090 GE Amsterdam, The Netherlands \\ ${ }^{4}$ Liverpool School of Tropical Medicine, Pembroke Place, Liverpool L3 5QA, UK
}

\begin{abstract}
Identifying how the interplay between neutral and adaptive evolutionary processes shapes the spatial structure of natural populations is a central task in ecology and conservation biology. In marine populations, generally characterised by large population sizes and high gene flow, the simultaneous use of multiple descriptors (i.e. genetic, morphological, life-history, etc.) can be particularly helpful in unravelling the often subtle and complex spatial patterns observed. The gastropod Buccinum undatum (common whelk) lacks a planktonic larval stage, which could promote isolation of local populations and lead to phenotypic divergence through genetic drift or local adaptation. Despite the commercial significance of this species, the relative importance of these 2 forces remains unknown. Here, we used microsatellites, geometric morphometrics and shell thickness measurements to investigate the evolutionary dynamics generating spatial variation in 10 whelk populations in coastal waters around Ireland. Genetic diversity was generally high and genetic structure moderate but significant (overall $F_{\mathrm{ST}}=0.019$ ), in accordance with an isolation-by-distance pattern. Phenotypic divergence, as measured by $P_{\mathrm{ST}}$, was uncorrelated with, and much more pronounced than, neutral divergence $\left(F_{\mathrm{ST}}\right)$, indicating that environmental variation rather than population isolation drives phenotypic differentiation. For some traits, at least, diversifying selection is likely to be involved unless additive genetic components of phenotypic variation among populations are very low. Our results document a lack of correspondence between neutral and adaptive divergence, and highlight the need to couple connectivity estimates with the assessment of ecologically relevant traits in fisheries management and conservation.
\end{abstract}

KEY WORDS: Adaptation $\cdot$ Genetic drift $\cdot$ Microsatellites $\cdot$ Geometric morphometrics $\cdot P_{\mathrm{ST}}$. Gastropoda $\cdot$ Buccinum undatum

\section{INTRODUCTION}

A major goal in conservation genetics, and evolutionary biology in general, is to understand the relative roles of neutral and adaptive forces in determining patterns of population differentiation. Such understanding is also pivotal for the conservation of intraspecific biodiversity in the case of endangered or highly exploited species (Hilborn et al. 2003). While recent advances in the field of molecular biology promise to pinpoint the genomic regions associated with specific phenotypic traits with increasingly greater speed and accuracy (Hohenlohe et al. 2010, Miller et al. 2011), there remains a constant and pressing need to generate reliable biological information, often at low operational costs, on a myriad 
of species and populations for the purpose of management (Waples et al. 2008) and conservation (Frankham 2010). To this end, approaches based on neutral genetic markers - traditionally employed to make inference on demographic connectivity must, where possible, be complemented with methods that can also provide information on adaptive processes across heterogeneous habitats (McKay \& Latta 2002, Räsänen \& Hendry 2008).

Marine species can present challenges to ecologists and conservation managers, as their large population sizes and high dispersal potential may result in weak patterns of differentiation (Hauser \& Carvalho 2008), which often hinder the effective implementation of genetic approaches in fisheries management and conservation (Waples et al. 2008). Yet, even in the marine realm, some species exhibit lifehistory traits, such as direct development and low vagility, that may promote population isolation (Colson \& Hughes 2004). One such species is the common whelk Buccinum undatum L. This large subtidal gastropod, though widely distributed across the North Atlantic shelf seas, lacks a dispersing planktonic stage and has limited mobility at the adult stage (Hancock 1963, Himmelman \& Hamel 1993). B. undatum (alongside lobster Homarus gammarus, brown crab Cancer pagurus and king scallop Pecten maximus) represents a key component of the Irish inshore shellfish industry, which yields $~ 50$ million euro and accounts for $50 \%$ of employment in the fishing sector (BIM 2005). Nevertheless, spatial population structure has never been taken into account for the purpose of management, possibly contributing to the recently observed depletion of the resource (Fahy 2008).

An extensive population genetic study across the NE Atlantic (Weetman et al. 2006) - but not including the Irish shelf — has shown that, while significant levels of genetic structuring in this species can occur locally at spatial scales of tens of $\mathrm{km}$, populations generally seem to have large neighbourhood sizes and are likely to maintain connectivity through a stepping-stone mechanism (Slatkin 1993). Here, we set out to investigate spatial population structure of whelk populations around Ireland, using both neutral genetic markers and phenotypic descriptors, in order to examine the independence or interplay of demographic and adaptive processes in the contemporary evolution of these populations.

Given the widely documented importance of shell morphology in the adaptation of gastropods (Vermeij 2002, Rolán-Alvarez et al. 2004, Hollander \& Butlin 2010, Auld \& Relyea 2011) and preliminary informa- tion on whelk shell variation around Ireland (Fahy et al. 2000, 2002), we used shell shape and thickness as morphological descriptors. We then employed recently devised approaches to estimate the additive genetic component of trait variation for species that are not easily amenable to common garden experiments (Saether et al. 2007, Brommer 2011), to compare possible patterns of phenotypic adaptation against the null hypothesis of a neutral background provided by microsatellite data.

\section{MATERIALS AND METHODS}

\section{Sampling}

A total of 493 individuals of Buccinum undatum were collected using baited pots or trawl from 10 locations around Ireland (Fig. 1, Table 1). Sampling focused on the eastern coast, as this is where the species is common and traditionally targeted by the fishery (Fahy et al. 2002, Fahy 2008), while populations from the west and north coasts are rarer and fragmented (BIM 2005). Whelks were frozen and subsequently thawed, after which the animals were removed from their shells. A piece of mantle tissue was preserved in $95 \%$ ethanol for genetic analyses, and the shell was cleaned, dried and stored for morpho-

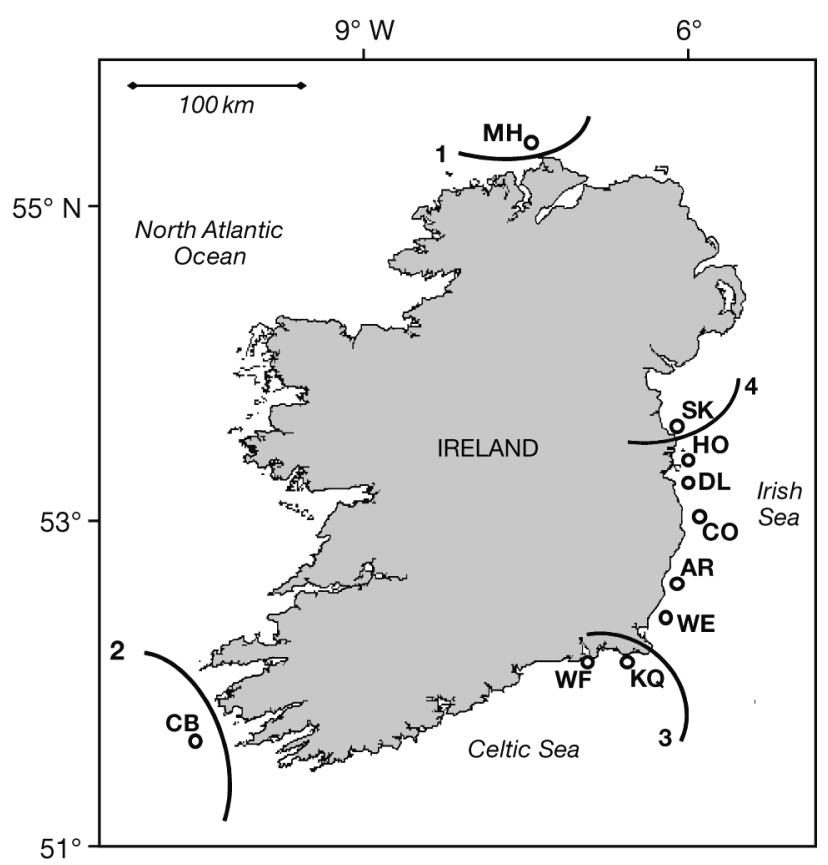

Fig. 1. Buccinum undatum. Map of Ireland indicating sampling localities; for codes see Table 1. Solid lines (numbered 1 to 4 , in order of decreasing importance) show main population 'barriers' identified using microsatellites 
Table 1. Buccinum undatum. Sample code, location, geographic coordinates and number of adult common whelks per sample (N) used in genetic (Gen.) and morphological (Morph.) analyses are given along with shell length (mm), shell weight ( $g$ ) and shell thickness (mean $\pm \mathrm{SE}_{\text {; }}$ residuals of a regression of the Principal Component 1 axis of shell thickness against shell length; see 'Materials and methods'). Letters in the final column summarize significant differences in shell thickness according to Tukey's pairwise test (groups sharing the same letter do not differ significantly from each other). Italics represent locations within the Irish Sea

\begin{tabular}{|c|c|c|c|c|c|c|c|c|c|c|}
\hline \multirow{2}{*}{$\begin{array}{l}\text { Sample } \\
\text { code }\end{array}$} & \multirow{2}{*}{ le Location } & \multicolumn{2}{|c|}{ Coordinates } & \multirow{2}{*}{$\begin{array}{c}\text { Date } \\
\text { (mo/yr) }\end{array}$} & \multicolumn{2}{|c|}{ Sample N } & \multicolumn{3}{|c|}{ Shell (mean \pm SE) } & \multirow[t]{2}{*}{ Tukey } \\
\hline & & $\begin{array}{l}\text { Lat. } \\
\text { (all N) }\end{array}$ & $\begin{array}{l}\text { Long. } \\
\text { (all W) }\end{array}$ & & Gen. & Morph. & Length & Weight & Thickness & \\
\hline $\mathrm{MH}$ & Malin Head & 55.22 & 07.03 & 05/06 & 52 & 29 & $106.07 \pm 1.04$ & $64.82 \pm 2.14$ & $0.141 \pm 0.013$ & $\mathrm{a}$ \\
\hline$S K$ & Skerries & 53.37 & 06.01 & $04 / 06$ & 22 & 17 & $110.46 \pm 2.03$ & $64.84 \pm 5.82$ & $0.038 \pm 0.028$ & $\mathrm{~b}, \mathrm{c}$ \\
\hline $\mathrm{HO}$ & Howth & 53.12 & 06.00 & 06/06 & 50 & 39 & $102.66 \pm 1.34$ & $45.42 \pm 1.66$ & $-0.052 \pm 0.010$ & $e, f$ \\
\hline$D L$ & Dun Laoghaire & 53.13 & 05.57 & 06/06 & 58 & 31 & $89.33 \pm 2.06$ & $25.74 \pm 1.43$ & $-0.093 \pm 0.008$ & $\mathrm{f}$ \\
\hline $\mathrm{CO}$ & Codling Buoy & 53.08 & 05.47 & 03/06 & 54 & 16 & $91.13 \pm 1.94$ & $32.82 \pm 2.51$ & $-0.020 \pm 0.010$ & $\mathrm{c}, \mathrm{d}, \mathrm{e}$ \\
\hline$A R$ & Arklow & 52.37 & 06.13 & 03/06 & 54 & 39 & $70.66 \pm 1.21$ & $16.51 \pm 0.99$ & $0.038 \pm 0.007$ & $\mathrm{~b}$ \\
\hline$W E$ & Wexford & 52.27 & 06.15 & 04/06 & 64 & 40 & $78.27 \pm 1.58$ & $20.43 \pm 1.26$ & $-0.027 \pm 0.005$ & $\mathrm{~d}, \mathrm{e}$ \\
\hline $\mathrm{KQ}$ & Kilmore Quay & 52.05 & 06.34 & 08/06 & 26 & 17 & $115.45 \pm 1.73$ & $79.82 \pm 4.16$ & $0.010 \pm 0.020$ & $\mathrm{~b}, \mathrm{c}, \mathrm{d}$ \\
\hline WF & Waterford & 52.13 & 06.56 & 08/06 & 59 & 43 & $75.45 \pm 0.81$ & $20.90 \pm 0.70$ & $0.029 \pm 0.007$ & $\mathrm{~b}, \mathrm{c}$ \\
\hline $\mathrm{CB}$ & Castletownbere & 51.33 & 10.50 & $10 / 06$ & 54 & 37 & $101.01 \pm 1.20$ & $50.42 \pm 1.91$ & $-0.028 \pm 0.010$ & d,e \\
\hline
\end{tabular}

logical analyses. All 493 individuals were used for genetic analysis; of these, 308 had relatively undamaged shells suitable for phenotypic analysis (shell thickness and shell shape) (Table 1).

\section{Morphological analysis}

Each shell was measured for length (from the tip of the whorl to the tip of the siphonal canal), weight and thickness (using 5 different points on the shell; see Fig. 2a,b). For thickness measurements, we used a digital calliper accurate to $0.01 \mathrm{~mm}$. In the laboratory, shells were then contrasted against the same dark background, mounted in a consistent orientation (Fig. 2) and photographed from the same distance and at the same angle. TPSDIG (Rohlf 2004) was used to place 11 landmarks (LM) on each shell image (Fig. 2c), which were chosen to represent total shell shape (Hollander et al. 2006). Only adult specimens (>50 mm shell length) on whose shells all landmarks were identifiable were included in subsequent analyses. TPSRELW (Rohlf 2004) was used to rotate, translate and scale landmark coordinates through generalized least squares superimposition (Rohlf \& Slice 1990). Residuals from the superimposition were analysed with the thin-plate spline (TPS) interpolating function, producing principal warps, followed by rel- ative warp analysis. Using TPSRELW we obtained centroid size (Bookstein 1991) and scores for each individual along a series of relative warps (RW), analogous to the eigenvectors of principal component analysis (PCA), which combined the major patterns of shape variation in the data set.

The 5 variables for shell thickness were reduced by applying PCA, and the resulting first principal component (PC1) was used in subsequent analyses as a multivariate measure of shell thickness (explaining $95 \%$ of shell thickness variance). PC1 correlated strongly with shell length (Fig. 3); hence, to obtain a size-independent measure of thickness across all 


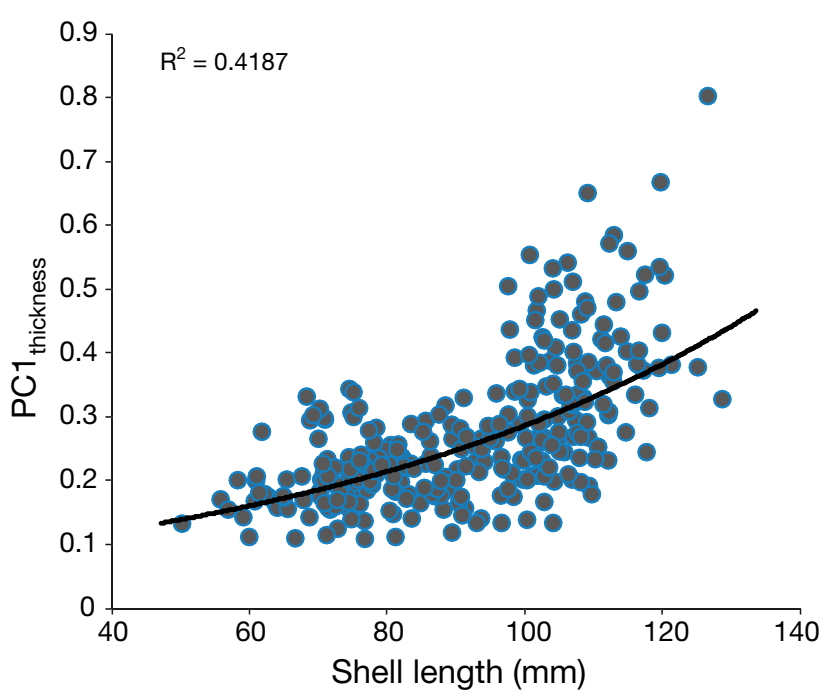

Fig. 3. Buccinum undatum. Principal Component 1 scores of shell thickness ( $\left.\mathrm{PC}_{\text {thickness }}\right)$ plotted against shell length, from all localities around Ireland. The non-linear trend line and relevant coefficient of determination $\left(\mathrm{R}^{2}\right)$ are also shown in the plot

populations, we first explored whether this size effect differed among collections: length and PC1 were log-transformed to satisfy the general linear model (GLM) assumption of homoscedasticity (Levene's test: $F_{9,298}=0.968 ; \mathrm{p}=0.467$ ), and data were analysed under GLM, with LogPC1 as response variable, 'population of origin' as predictor variable and LogLength as covariate. No significant interaction was detected between population of origin and LogLength $\left(F_{9,288}=\right.$ $1.116 ; \mathrm{p}=0.351$ ), indicating that variation in thickness between populations is independent of the effect of length (see Fig. A1 and Table A1 in Appendix 1). Thus, we used the residuals of a regression of PC1 against shell length according to the power function: PC1 $=a L^{b}$ (Fig. 3 ) as a measure of variance in thickness that is not accounted for by shell size. Spatial variation in residual shell thickness was finally investigated using 1-way analysis of variance (ANOVA) and Tukey's post hoc tests.

We extracted 18 RWs and used the first 2 RW axes to visualise shell shape variation within and among populations. RW1 was significantly correlated with centroid size and was corrected by applying a quadratic regression and using the residuals of RW1 in all further analyses of shell shape. Repeatability of all RWs was obtained using Pearson's correlation coefficient between RW scores extracted from the same images of 196 whelk specimens on which landmarks were independently digitized by 2 observers.
Shell shape differentiation among locations was tested using a non-parametric analysis of similarities (ANOSIM, 10000 randomisations) based on Euclidean distance derived from the first 3 RWs (see 'Results'), as implemented in PAST (Hammer et al. 2001). Finally, we used discriminant function analysis (DFA) on all extracted RWs to identify the shape variables that maximize differences between populations. Unless otherwise indicated, statistical analyses were carried out using PASW 18 (SPSS ${ }^{\circledR}$ Inc.).

\section{Genetic analysis}

Genomic DNA was obtained from $\sim 5 \mathrm{~mm}^{2}$ of mantle tissue using the Nucleon Genomic DNA extraction kit (Tepnel Life Sciences). We used $100 \mathrm{ng}$ of DNA as input in separate PCR reactions to amplify 5 microsatellite loci isolated from Buccinum undatum with locus-specific conditions (Weetman et al. 2005). Each $15 \mu \mathrm{l}$ PCR reaction further contained $0.5 \mu \mathrm{l}$ $\mathrm{MgCl}_{2}(50 \mathrm{mM}), 1.5 \mu \mathrm{l}$ of $10 \times \mathrm{PCR}$ buffer (Invitrogen), $1.5 \mu \mathrm{l}$ dNTPs (GATC $2 \mathrm{mM}$ each), $0.15 \mu \mathrm{l}$ of each primer $(10 \mu \mathrm{M}), 0.1 \mu \mathrm{l}$ Taq $\left(5 \mathrm{U} 0.1 \mu \mathrm{l}^{-1}\right)$ and $\mathrm{ddH}_{2} \mathrm{O}$. Each forward primer was fluorescently labelled, permitting amplified fragments to be visualized on an ABI $3130 x l$ sequencer and sizes to be determined by comparison to an internal lane standard (LIZ500 ${ }^{\circledR}$, Applied Biosystems) using GeNEMAPPER ${ }^{\circledR}$.

We analysed genetic variation in a total dataset of 493 adult whelks from 10 populations (Table 1). Raw microsatellite data were examined for scoring errors, and the possible occurrence of null alleles, using Micro-CHECKer (van Oosterhout et al. 2004). Nonstepwise alleles (exhibiting a fragment size incongruent with the expected repeat motif) were observed at locus Bu122, but all alleles were included in the analysis. Microsatellite diversity within samples was estimated as allelic richness and Nei's (1987) unbiased expected heterozygosity $\left(H_{\mathrm{e}}\right)$ using FSTAT 2.9.3.2 (Goudet 1995). Genotypes at all pairs of loci were tested for gametic phase disequilibrium, and deviations from Hardy-Weinberg equilibrium (HWE) were calculated using Weir \& Cockerham's (1984) inbreeding coefficient $\left(F_{\mathrm{IS}}\right)$ in GENEPOP 3.4 (Raymond \& Rousset 1995). The linkage disequilibrium method implemented in LDNE (Waples \& Do 2008) was employed to gauge estimates of effective population size, $N_{\mathrm{e}}$, excluding alleles with frequencies $<0.02$, as recommended by the authors. Locus departures from HWE were assessed using 2-tailed exact tests and the Markov chain method in GENEPOP. For these, and all subsequent analyses involving multiple simulta- 
neous tests, significance levels were adjusted by a sequential Bonferroni procedure using an initial $\alpha$ level of 0.05 .

We estimated population structure among samples using Weir \& Cockerham's (1984) estimator of $F_{\mathrm{ST}}$, and tested the null hypothesis of identical allele frequency distributions across samples using Markov chain exact tests of genic differentiation in GENEPOP (each test used 100 batches and 10000 iterations). In order to investigate the effect of geography on genetic structuring, we first used a Mantel test (Mantel 1967) to determine if there was an association between the pairwise matrices of genetic differentiation and geographic distance. Next, we identified the most important geographic discontinuities of genetic variation using the software BARRIER 2.2 (Manni et al. 2004). This software identifies any geographic discontinuities in genetic differentiation ('barriers') using geographic coordinates and a distance matrix, which in this case was represented by the matrix of pairwise $F_{\mathrm{ST}}$ values among populations. Finally, we estimated the partitioning of total genetic variation at different hierarchical spatial levels using an analysis of molecular variance (AMOVA) in ARLEQUIN 3.1 (Excoffier et al. 2006) (AMOVA design illustrated in the 'Results').

\section{Comparison between genetic and phenotypic data}

Two multidimensional scaling (MDS) plots were inferred from, respectively, the pairwise $F_{\mathrm{ST}}$ matrix and a Euclidean distance matrix based on RWs, in order to compare the relative differences among populations based on both genetic and morphological descriptors. The same matrices were also used in a Mantel test (Mantel 1967) to test for their degree of congruence.

If both are measured without error, neutral genetic differentiation - as measured by $F_{\mathrm{ST}}$-is analogous to additive genetic differentiation in quantitative traits - as measured by $Q_{\mathrm{ST}}$ (Spitze 1993). Where the confidence intervals of $F_{\mathrm{ST}}$ and $Q_{\mathrm{ST}}$ overlap, phenotypic traits are deemed to be evolving at the same rate as neutral markers, making it difficult to disentangle the relative contributions of random genetic drift and natural selection to the patterns observed. If $Q_{\mathrm{ST}}>F_{\mathrm{ST}}$, diversifying selection (where different phenotypes are favoured in different populations) is invoked, whereas $Q_{\mathrm{ST}}<F_{\mathrm{ST}}$ suggests stabilising selection (the same phenotype is favoured across populations). Accurate measurement of $Q_{\mathrm{ST}}$ is very difficult (e.g. Whitlock 2008), because estimation of additive variances requires multigenerational laboratory common-garden experiments, which are unfeasible for long-lived species such as Buccinum undatum. A commonly applied alternative is the phenotypic 'analogue' $P_{\mathrm{ST}}$, which is simply estimated from the between population $\left(V_{\mathrm{B}}\right)$ and within population $\left(V_{\mathrm{W}}\right)$ phenotypic components of variation (Merilä 1997). $P_{\mathrm{ST}}$ has often been used interchangeably with $Q_{\text {ST }}$ (Merilä \& Crnokrak 2001, Leinonen et al. 2008), typically assuming $c=1$ and $h^{2}=0.5$ (Saether et al. 2007), where $c$ is the between-population additive genetic component and $h^{2}$ is the within-population additive genetic component ('narrow-sense heritability'). However, recently, Brommer (2011) argued that, especially in cases of diversifying selection, environmental and non-additive genetic components of phenotypic variation among populations are likely to be substantial and, probably, much greater than $h^{2}$ (rather than much less as assumed when equating $P_{\mathrm{ST}}$ directly with $Q_{\mathrm{ST}}$ ). Therefore, Brommer (2011) suggested the alternative formulation:

$$
P_{\mathrm{ST}}=c V_{\mathrm{B}} /\left(c V_{\mathrm{B}}+2 h^{2} V_{\mathrm{W}}\right)
$$

Rather than specific values of $c$ and $h^{2}$ (which are generally unknown) it is their ratio which determines whether conclusions that $Q_{\mathrm{ST}}$ (estimated as $P_{\mathrm{ST}}$ ) deviates from the null hypothesis provided by $F_{\mathrm{ST}}$ may be appropriately conservative; low values (e.g. $c / h^{2}<0.2$ ) suggest more robust conclusions (Brommer 2011). Therefore, we first generated overall and pairwise $P_{\mathrm{ST}}$ estimates, and secondly determined the minimum value of $c / h^{2}$ required for each phenotypic trait to produce non-overlapping confidence limits between $P_{\mathrm{ST}}$ and $F_{\mathrm{ST}}$.

Recently, there has been much discussion as to the efficacy of the use of conventional $F_{\mathrm{ST}}$ in population genetic studies, mainly related to the expected downward bias associated with highly polymorphic loci (Hedrick 2005, Jost 2008, Ryman \& Leimar 2009, Whitlock 2011). However, since the expectation of parity with $Q_{\mathrm{ST}}$ does not hold for alternative standardized metrics (Edelaar \& Björklund 2011, Meirmans \& Hedrick 2011, Whitlock 2011), we concentrated our analysis on $F_{\mathrm{ST}}$.

Most studies comparing neutral and quantitative genetic variation primarily focus on the overall difference between $F_{\mathrm{ST}}$ and $Q_{\mathrm{ST}}$, but comparison of pairwise patterns of phenotypic and genetic differentiation can provide additional information, because, if the former are evolving neutrally, congruence between matrices would be expected. Thus, we conducted a series of Mantel tests between the pairwise $P_{\mathrm{ST}}$ values and geographic distance, as well as be- 
Table 2. Buccinum undatum. Estimates of genetic and morphological differentiation between samples. Multi-locus $F_{\mathrm{ST}}$ values are reported below the diagonal; $R$-values obtained through an ANOSIM procedure based on Euclidean distances of relative warp scores are above the diagonal. Significant deviations from genetic homogeneity (exact test) and significant ANOSIM coefficients (after 10000 randomizations) are shown in bold if remaining significant after sequential Bonferroni correction. Italics represent comparisons within the Irish Sea. Sample codes are detailed in Table 1

\begin{tabular}{|lccccccccrr|}
\hline Sample code & MH & SK & HO & DL & CO & AR & WE & KQ & WF & CB \\
\hline MH & - & 0.175 & $\mathbf{0 . 1 8 2}$ & $\mathbf{0 . 1 6 4}$ & 0.158 & $\mathbf{0 . 2 2 3}$ & $\mathbf{0 . 2 3 3}$ & $\mathbf{0 . 2 2 5}$ & $\mathbf{0 . 2 5 0}$ & $\mathbf{0 . 1 3 7}$ \\
SK & $\mathbf{0 . 0 5 8}$ & - & 0.078 & 0.178 & 0.001 & -0.005 & 0.089 & 0.067 & 0.151 & 0.178 \\
HO & $\mathbf{0 . 0 4 4}$ & -0.004 & - & $\mathbf{0 . 2 2 1}$ & 0.076 & 0.031 & $\mathbf{0 . 1 8 9}$ & 0.044 & -0.001 & $\mathbf{0 . 2 2 6}$ \\
DL & $\mathbf{0 . 0 3 8}$ & 0.001 & -0.001 & - & 0.042 & $\mathbf{0 . 2 8 2}$ & 0.063 & $\mathbf{0 . 3 1 0}$ & $\mathbf{0 . 3 4 2}$ & $\mathbf{0 . 4 5 3}$ \\
CO & $\mathbf{0 . 0 2 4}$ & $\mathbf{0 . 0 1 2}$ & 0.004 & 0.000 & - & 0.059 & 0.021 & 0.117 & 0.170 & $\mathbf{0 . 2 6 7}$ \\
AR & $\mathbf{0 . 0 3 2}$ & $\mathbf{0 . 0 1 9}$ & $\mathbf{0 . 0 0 5}$ & -0.002 & 0.004 & - & $\mathbf{0 . 1 7 1}$ & 0.059 & 0.051 & $\mathbf{0 . 1 5 1}$ \\
WE & $\mathbf{0 . 0 3 1}$ & $\mathbf{0 . 0 1 3}$ & $\mathbf{0 . 0 0 7}$ & -0.002 & -0.001 & -0.003 & - & $\mathbf{0 . 3 3 0}$ & $\mathbf{0 . 3 1 7}$ & $\mathbf{0 . 3 9 7}$ \\
KQ & $\mathbf{0 . 0 5 3}$ & -0.009 & -0.007 & -0.003 & $\mathbf{0 . 0 1 1}$ & $\mathbf{0 . 0 1 0}$ & $\mathbf{0 . 0 1 1}$ & - & 0.042 & $\mathbf{0 . 2 4 5}$ \\
WF & $\mathbf{0 . 0 8 2}$ & $\mathbf{0 . 0 1 8}$ & $\mathbf{0 . 0 0 9}$ & $\mathbf{0 . 0 0 6}$ & $\mathbf{0 . 0 2 2}$ & $\mathbf{0 . 0 1 2}$ & $\mathbf{0 . 0 1 4}$ & $\mathbf{0 . 0 0 9}$ & - & $\mathbf{0 . 2 1 7}$ \\
CB & $\mathbf{0 . 0 6 0}$ & $\mathbf{0 . 0 1 0}$ & $\mathbf{0 . 0 1 2}$ & $\mathbf{0 . 0 2 4}$ & $\mathbf{0 . 0 2 0}$ & $\mathbf{0 . 0 3 4}$ & $\mathbf{0 . 0 3 2}$ & $\mathbf{0 . 0 0 5}$ & $\mathbf{0 . 0 3 4}$ & - \\
\hline
\end{tabular}

tween each $P_{\mathrm{ST}}$ matrix and the $F_{\mathrm{ST}}$ matrix $(100000$ randomizations each). If 3 matrices appeared to be associated with each other, we used partial Mantel tests to control for and detect the potential effect of multi-collinearity between pairs of matrices.

PAST (Hammer et al. 2001) was used to generate MDS plots and PopTools 2.3 (Hood 2010) was used to generate bootstrap confidence intervals for $P_{\mathrm{ST}}$ analyses. Simple and partial Mantel tests were performed with ZT (Bonnet \& van de Peer 2002).

\section{RESULTS}

\section{Phenotypic variation}

Mean length and weight per sample of Buccinum undatum shells are summarised in Table 1. Overall PC-inferred shell thickness, after correction for the effect of size (see 'Materials and methods'), was found to differ significantly among populations $\left(F_{9,298}\right.$ $=36.459, \mathrm{p}<0.001$; Table 1$)$. MH shells from the northern Atlantic coast were significantly thicker than all other samples, whereas DL shells from the Irish Sea were the thinnest (for sample codes see Table 1).

Since RW1, RW2 and RW3 were the only consistently repeatable relative warps (Pearson correlation coefficients: $r=0.996,0.840$, and 0.877 , respectively) and explained a total of $65.7 \%$ of the variance, we focused specifically on these 3 RWs to further investigate phenotypic variation. Overall shell shape variation among populations was highly significant (ANOSIM, global $\mathrm{R}=0.176 ; \mathrm{p}<<0.001$ ), with nearly half of pairwise comparisons being significant after correction for multiple testing (Table 2). RW1 repre- sented variation from broad/round/short shells (e.g. $\mathrm{AR}$ and WF) to narrow/slender/long shells (e.g. CB, $\mathrm{MH}$, SK and HO), and RW2 represented variation from narrow shell apertures (e.g. DL) to wide shell apertures (e.g. AR, KQ, SK) (Fig. 4). Discriminant function analysis showed that the first canonical variate explained $40.3 \%$ of the variance in shell shape and was most strongly correlated with RW3 $(\mathrm{r}=$ 0.504), indicating that RW3 produced the greatest partitioning of sample sites. High RW3 scores correspond to a tighter and more elongated siphonal end and a smaller aperture, whereas low scores along RW3 reflect a truncated and wide open end of this part of the shell (Fig. 5).

\section{Genotypic variation}

There was no evidence for significant linkage disequilibrium between microsatellite loci. Significant departures from Hardy-Weinberg expectations were observed in all samples for Bu145, 1 sample for Bu151 and 5 out of 10 samples for Bu76 (Table 3). In all cases, these deviations resulted from heterozygote deficiencies. The consistency of observations across sample sites for Bu145 and Bu76 suggests the presence of null alleles as the most probable cause for the departures from Hardy-Weinberg expectations and is consistent with the findings of Weetman et al. (2006) for these loci. Following these authors, we used Brookfield's (1996) method ('Brookfield 1' in MiCRO-CHECKER) to estimate null allele frequencies ( $\mathrm{r}$; Table 3) for Bu145 and $\mathrm{Bu} 76$, and generated a dataset that included the null alleles recoded as missing data. All subsequent analyses are based on this corrected dataset. Levels of heterozygosity and allelic richness were very similar 

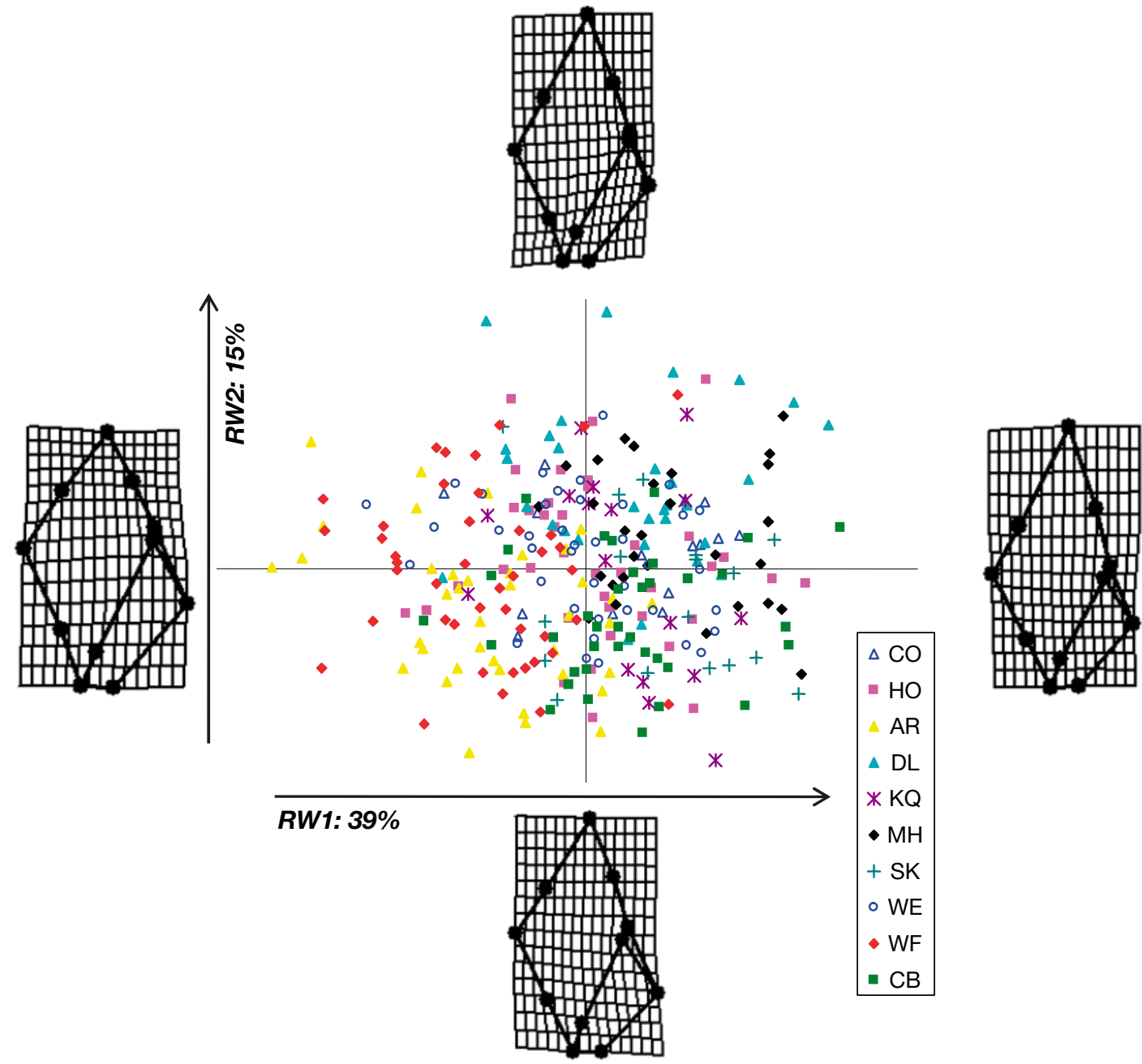

Fig. 4. Buccinum undatum. Shell shape variation within and among 10 collections of common whelk. Ordination of data in the plane identified by relative warp (RW) Axis 1 (explaining 39.15\% of variance) and RW2 (explaining $15.00 \%$ of variance). Corresponding thin-plate splines of the most positive and negative deformations along the axes are indicated. Sample codes are detailed in Table 1

Fig. 5. Buccinum undatum. Mean and $95 \%$ confidence intervals (bars) of RW3 scores among populations. The 2 extreme splines along the RW3 axis are also depicted. Sample codes are detailed in Table 1

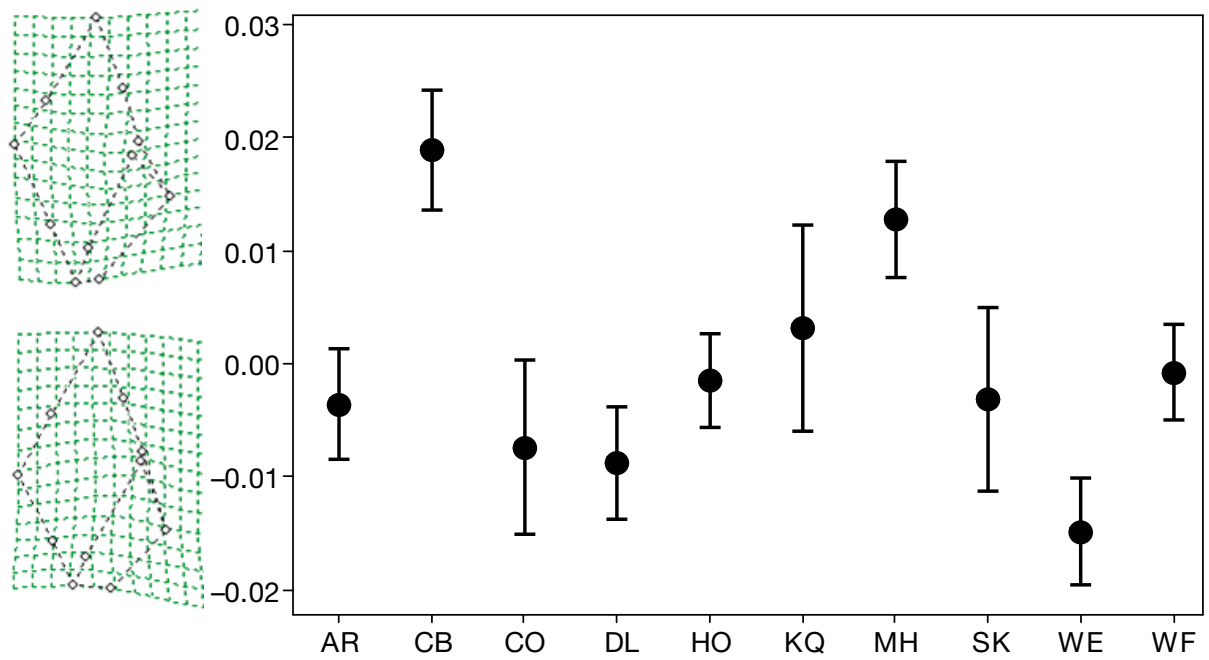


Table 3. Buccinum undatum. Population genetic variability estimates per locus and across loci for common whelks: locus names (Bu119, Bu122, Bu145, Bu151, Bu76), sample size $(\mathrm{N})$, allelic richness $(\hat{A})$, inbreeding coefficient $\left(F_{\mathrm{IS}}\right.$, significant values in bold), expected heterozygosity $\left(H_{\mathrm{e}}\right)$ and, for loci Bu145 and Bu76, the null allele frequencies as estimated by Brookfield's

(1996) Estimator 1 (r). Sample codes are detailed in Table 1

\begin{tabular}{|c|c|c|c|c|c|c|c|c|c|c|c|c|c|c|c|c|c|c|c|c|}
\hline \multirow{2}{*}{$\begin{array}{l}\text { Sample } \\
\text { code }\end{array}$} & \multirow[t]{2}{*}{$\mathrm{N}$} & \multicolumn{3}{|c|}{ Bu119 } & \multicolumn{3}{|c|}{ Bu122 } & \multicolumn{4}{|c|}{-Bu145 } & \multicolumn{3}{|c|}{ Bu151 } & \multicolumn{4}{|c|}{-Bu76 } & \multicolumn{2}{|c|}{ Mean } \\
\hline & & $\hat{A}$ & $F_{\mathrm{IS}}$ & $H_{\mathrm{e}}$ & $\hat{A}$ & $F_{\mathrm{IS}}$ & $H_{\mathrm{e}}$ & $\hat{A}$ & $F_{\mathrm{IS}}$ & $H_{\mathrm{e}}$ & $\mathrm{r}$ & $\hat{A}$ & $F_{\mathrm{IS}}$ & $H_{\mathrm{e}}$ & $\hat{A}$ & $F_{\mathrm{IS}}$ & $H_{\mathrm{e}}$ & $\mathrm{r}$ & $\hat{A}$ & $H_{\mathrm{e}}$ \\
\hline $\mathrm{MH}$ & 52 & 5.1 & 0.07 & 0.69 & 11.5 & 0.07 & 0.87 & 3.6 & 0.72 & 0.56 & 0.25 & 15.4 & 0.08 & 0.94 & 2.8 & 0.51 & 0.52 & 0.17 & 7.7 & 0.71 \\
\hline SK & 22 & 3.0 & 0.11 & 0.62 & 14.6 & 0.02 & 0.88 & 5.0 & 0.69 & 0.73 & 0.28 & 14.0 & -0.02 & 0.93 & 2.9 & 0.27 & 0.25 & 0 & 7.9 & 0.68 \\
\hline $\mathrm{HO}$ & 50 & 4.0 & 0.09 & 0.66 & 11.3 & 0.07 & 0.88 & 4.3 & 0.74 & 0.66 & 0.29 & 16.2 & 0.11 & 0.95 & 3.0 & 0.26 & 0.30 & 0 & 7.8 & 0.69 \\
\hline DL & 58 & 3.7 & 0.05 & 0.66 & 14.0 & 0.03 & 0.90 & 4.6 & 0.53 & 0.62 & 0.20 & 16.4 & 0.02 & 0.94 & 2.8 & 0.70 & 0.29 & 0.15 & 8.3 & 0.68 \\
\hline $\mathrm{CO}$ & 54 & 3.9 & 0.09 & 0.68 & 12.8 & 0.14 & 0.89 & 3.9 & 0.77 & 0.63 & 0.29 & 14.9 & 0.17 & 0.94 & 2.8 & 0.68 & 0.46 & 0.21 & 7.7 & 0.72 \\
\hline AR & 54 & 4.0 & -0.04 & 0.61 & 13.9 & 0.00 & 0.90 & 3.6 & 0.69 & 0.59 & 0.25 & 15.3 & 0.10 & 0.94 & 3.0 & 0.37 & 0.38 & 0.10 & 7.9 & 0.68 \\
\hline WE & 64 & 4.0 & 0.01 & 0.63 & 13.7 & -0.06 & 0.90 & 4.3 & 0.69 & 0.62 & 0.26 & 15.5 & 0.09 & 0.93 & 3.6 & 0.35 & 0.44 & 0.10 & 8.2 & 0.71 \\
\hline KQ & 26 & 4.0 & -0.11 & 0.66 & 11.4 & -0.12 & 0.89 & 5.9 & 0.79 & 0.73 & 0.32 & 16.6 & -0.02 & 0.94 & 3.6 & 0.22 & 0.26 & 0 & 8.3 & 0.69 \\
\hline WF & 59 & 4.4 & 0.05 & 0.63 & 13.7 & -0.02 & 0.91 & 3.3 & 0.54 & 0.57 & 0.19 & 16.2 & 0.06 & 0.94 & 2.1 & 1.00 & 0.07 & 0.06 & 8.0 & 0.62 \\
\hline $\mathrm{CB}$ & 54 & 5.0 & 0.06 & 0.69 & 13.3 & 0.02 & 0.91 & 6.4 & 0.53 & 0.81 & 0.23 & 15.4 & -0.01 & 0.93 & 3.5 & 0.39 & 0.33 & 0.09 & 8.7 & 0.73 \\
\hline
\end{tabular}
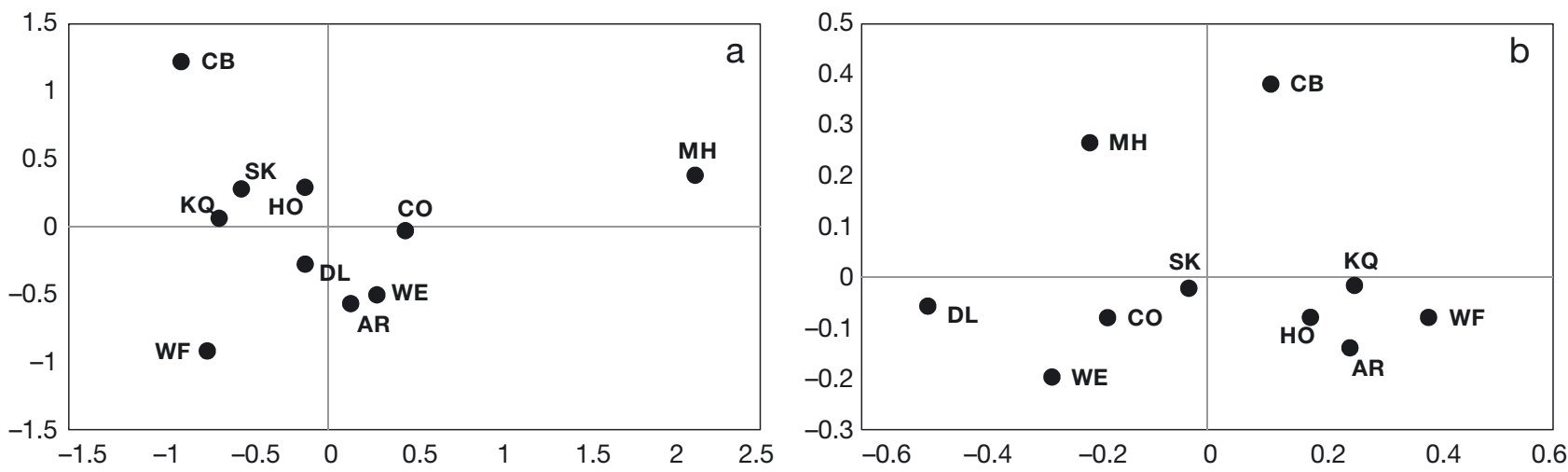

Fig. 6. Buccinum undatum. Multidimensional scaling plots inferred from: (a) pairwise $F_{\mathrm{ST}}$ values obtained by means of microsatellite analysis and (b) a matrix of Euclidean distances based on morphometric variation (see 'Results'). Sample codes are detailed in Table 1

across populations (Table 3). Estimates of effective population size were 'infinite' for all populations except for $\operatorname{AR}\left(\hat{N_{e}}=104, \mathrm{CI}: 48\right.$ to 1380$)$ and $\mathrm{CB}\left(\hat{N_{e}}=91\right.$, $\mathrm{CI}: 47$ to 350$)$. Overall population substructure was significant $\left(F_{\mathrm{ST}}=0.019\right.$; bootstrapped $95 \%$ confidence limits: 0.0035 to 0.047 ) and the vast majority of pairwise population comparisons were significant (Table 2). Even within the Irish Sea there seems to be a divergence between northern (SK and HO) and southern (AR and WE) locations.

The strongest geographical discontinuities inferred using BARRIER are illustrated in Fig. 1, each corresponding to progressively decreasing levels of $F_{\mathrm{ST}}$ differentiation. Barriers are consistent with the geographical separation of locations, with the first and second breaks separating, respectively, (1) the $\mathrm{MH}$ north-western and (2) the CB south-western Atlantic samples, and the third break separating the Celtic from the Irish Sea areas (3). The fourth barrier lies between the northernmost Irish Sea sample, SK, and all other locations within that basin. Further statistical insight into geographic structure is provided by the AMOVA results: the 5-group structure indicated by BARRIER (with 1: $\mathrm{MH}_{;} 2: \mathrm{CB} ; 3: \mathrm{WF}+\mathrm{KQ}_{i} 4: \mathrm{SK}_{;}$: $\mathrm{HO}+\mathrm{DL}+\mathrm{DL}+\mathrm{AR}+\mathrm{WE}$ ) corresponded to an among-group differentiation nearly 7 times greater $\left(F_{\mathrm{CT}}=0.027, \mathrm{p}<<0.001\right)$ than within-group variance $\left(F_{\mathrm{SC}}=0.004, \mathrm{p}<0.05\right)$. Closer examination of pairwise $F_{\text {ST }}$ values (Table 2) showed that $\mathrm{HO}$ exhibits some significant divergence from more southern Irish Sea locations and that $\mathrm{KQ}$ is more divergent from the nearby WF than from some of the Irish Sea localities (Fig. 6a). The placement of $\mathrm{HO}$ with SK and of $\mathrm{KQ}$ with the Irish Sea group effectively removes the within-group variance $\left(F_{\mathrm{SC}}=0.001, \mathrm{p}=0.2\right)$ and marginally increases the among-group differentiation 
$\left(F_{\mathrm{CT}}=0.029, \mathrm{p} \ll 0.001\right)$. Neutral genetic divergence was correlated with geographic distance (Mantel test, $r=0.70, p=0.009$; Fig. 7a).

\section{Comparison of phenotypic versus genotypic differentiation}

The overall patterns of genetic and phenotypic differentiation are rather discordant (Fig. 6), and a Mantel test confirms that shell shape distances among populations are not correlated with neutral genetic divergence $(r=0.13, p=0.24)$. Consequently, shell shape does not correlate with geographic distance (r $=0.03, \mathrm{p}=0.40$ ).

We obtained much higher point estimates of $P_{\mathrm{ST}}$ than of $F_{\mathrm{ST}}$, for all 4 main morphological descriptors (RW1, RW2, RW3 and shell thickness) (Table 4). However, $c / h^{2}$ ratios required to produce $P_{\mathrm{ST}}$ values significantly larger than $F_{\mathrm{ST}}$ varied considerably, being low for shell thickness, much higher for RW1 and RW2, and intermediate for RW3 (Table 4). This suggests a potentially robust conclusion of $Q_{\mathrm{ST}}>$ $F_{\mathrm{ST}}$ for shell thickness, somewhat greater uncertainty for RW3, but limited confidence that $Q_{\mathrm{ST}}>F_{\mathrm{ST}}$ for RW1 and RW2.

None of the $P_{\mathrm{ST}}$ matrices for the 4 morphological descriptors were significantly correlated with $F_{\mathrm{ST}}$ differentiation (Table 5), though correlation for RW3 was marginal ( $\mathrm{p}=0.07$ ). RW3 $P_{\mathrm{ST}}$ was also the only phenotypic measure to be correlated with geographic distance $(p=0.01)$ (Fig. $7 b)$. Thus, we performed another (partial)
Table 4. Buccinum undatum. Point estimates of $P_{\mathrm{ST}}$ and $95 \%$ confidence limits for the 4 key phenotypic descriptors, compared to a baseline of neutral genetic variation as obtained through conventional $F_{\mathrm{ST}}$ inferred from microsatellite data. Critical $c / h^{2}$ values, above which the confidence limits of $P_{\mathrm{ST}}$ and $F_{\mathrm{ST}}$ do not overlap, are reported in the last column (the lower the critical $c / h^{2}$ ratio, the more robust is the difference in magnitude between $P_{\mathrm{ST}}$ and $F_{\mathrm{ST}}$ ). All confidence intervals (CI) were obtained after 1000 bootstrap replicates. RW: relative warp; PC: principal component

\begin{tabular}{|lccc|}
\hline & Point estimate & 95\% CI & \multicolumn{1}{c|}{$c / h^{2}$ crit. } \\
\hline $\boldsymbol{P}_{\text {ST }}$ (morphology) & & & \\
RW1 (residual) & 0.220 & $(0.164-0.327)$ & 0.50 \\
RW2 & 0.219 & $(0.167-0.322)$ & 0.50 \\
RW3 & 0.350 & $(0.291-0.447)$ & 0.28 \\
Thickness & 0.545 & $(0.490-0.635)$ & 0.11 \\
$\quad$ (PC1_residual) & & & \\
Microsatellite data & & & \\
$F_{\text {ST }}$ & 0.019 & $(0.004-0.047)$ & \\
\hline
\end{tabular}

Table 5. Buccinum undatum. Mantel tests (simple and partial) among pairwise matrices of geographic (Geo.Dist.), genetic $\left(F_{\mathrm{ST}}\right)$ and phenotypic (RW1, RW2, RW3, thickness) differentiation. Values in bold are significant. RW: relative warp; PC: principal component

\begin{tabular}{|c|c|c|c|c|c|}
\hline & \multicolumn{2}{|c|}{ Simple Mantel } & & \multicolumn{2}{|c|}{ Partial Mantel } \\
\hline & $\mathrm{r}$ & $\mathrm{p}$ & & $\mathrm{r}$ & $\mathrm{p}$ \\
\hline$F_{\text {ST }}$ vs. Geo.Dist. & 0.701 & 0.009 & & & \\
\hline$F_{\text {ST }}$ vs. RW1_residual & 0.167 & 0.156 & & & \\
\hline$F_{\mathrm{ST}}$ vs. RW2 & 0.017 & 0.407 & & & \\
\hline$F_{\mathrm{ST}}$ vs. RW3 & 0.396 & 0.073 & $\begin{array}{l}\text { Controlling } \\
\text { for Geo.Dist. }\end{array}$ & -0.010 & 0.480 \\
\hline $\begin{array}{l}F_{\mathrm{ST}} \text { vs. Thickness } \\
\text { (PC1_residual) }\end{array}$ & 0.316 & 0.135 & & & \\
\hline $\begin{array}{l}\text { RW1_residual } \\
\text { vs. Geo.Dist. }\end{array}$ & -0.005 & 0.425 & & & \\
\hline RW2 vs. Geo.Dist. & 0.160 & 0.253 & & & \\
\hline RW3 vs. Geo.Dist. & 0.629 & 0.014 & Controlling for $F_{\mathrm{ST}}$ & $\mathbf{0 . 6 2 0}$ & 0.007 \\
\hline $\begin{array}{l}\text { Thickness(PC1_residual) } \\
\text { vs. Geo.Dist. }\end{array}$ & 0.197 & 0.265 & & & \\
\hline
\end{tabular}
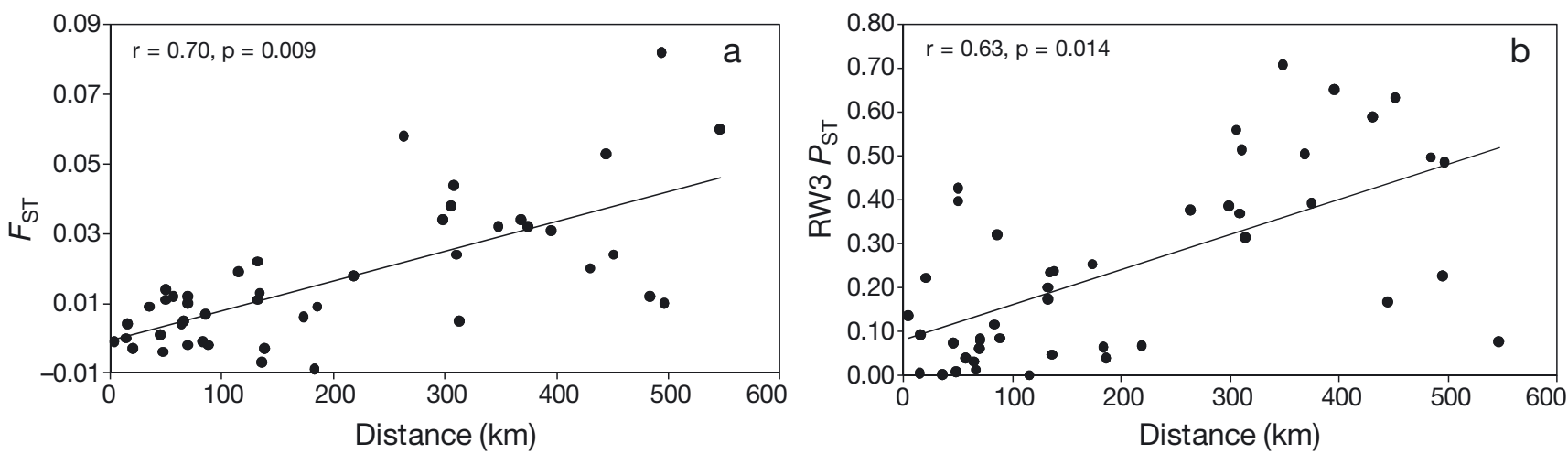

Fig. 7. Buccinum undatum. Isolation-by-distance plots of $F_{\mathrm{ST}}(\mathrm{a})$ and $P_{\mathrm{ST}}$ RW3 (b) values against the geographic distance among pairs of samples 
Mantel test between RW3 and geographic distance, this time 'controlling' for $F_{\mathrm{ST}}$. RW3 $P_{\mathrm{ST}}$ still proved to be robustly correlated with geographic distance, but, conversely, a test between $F_{\mathrm{ST}}$ and RW3 $P_{\mathrm{ST}}$, 'controlling' for geographic distance, decisively rejected any association between the matrices (Table 5).

The relationship between RW3 and geographic distance seems to rest almost entirely on the higher scores arising from pairwise comparisons involving distances $>250 \mathrm{~km}$, which involve samples from outside the Irish Sea, particularly CB and MH. Indeed, a closer look at Fig. 7b shows that the 'cloud' of data points $<250 \mathrm{~km}$ do not follow an isolation-bydistance pattern.

\section{DISCUSSION}

The present study detected strong patterns of genetic and phenotypic differentiation among whelk Buccinum undatum populations on the Irish shelf. Neutral genetic variation was rather consistent with expectations based on the life-history of the species - which lacks a planktonic larval stage - and the geography of the study area. Direct development from benthic egg masses is expected to limit longdistance dispersal, and the existence of straits, north and south of the Irish Sea, likely plays a role in determining demographic separation. Phenotypic variation was often pronounced, but was uncorrelated with $F_{\mathrm{ST}}$, and, for some traits at least, the patterns of $P_{\text {ST }}$ were inconsistent with those observed at neutral loci, which points towards the influence of environmental heterogeneity and not genetic drift as the primary driver of variation at ecologically relevant traits. Such morphological variation probably reflects the interplay between genetic adaptation and shortterm plasticity (Merilä \& Sheldon 1999, Vermeij 2002, Pigliucci 2005). Collectively, the results of the present study are informative, not only as they provide a neutral framework to understand demographic connectivity in a commercially exploited species, but also because they suggest the likely existence of ecological selection and local adaptation. This can both help improving management targets and pave the way for additional investigations.

\section{Neutral genetic variation}

The present genetic data allow for a direct comparison with a recent study conducted using the same marker loci over a broader area of the NE Atlantic
(Weetman et al. 2006), albeit excluding Irish locations. We found an overall level of spatial population structuring greater than that detected by Weetman et al. (2006) among populations distributed along the western, southern and eastern coasts of Britain. The most important genetic breaks (Fig. 1) correspond with known geographical and oceanographic features (Horsburgh et al. 2000, Brown et al. 2003), and the overall pattern follows a typical isolation-by-distance model, more pronounced than that detected by Weetman et al. (2006). Even within the Irish Sea, there seems to be a trend for more distantly located samples to exhibit greater genetic differentiation (Mantel, $\mathrm{r}=0.45, \mathrm{p}=0.06$ ), with samples in the central portion of the Irish Sea, DL and CO, not significantly divergent from SK or HO in the north, nor from $\mathrm{AR}$ and WE in the south. This suggests that gene flow counterbalances the effect of drift and that the Irish Sea populations are to some extent demographically connected.

On the other hand, there seems to be a definite separation of the Atlantic populations, $\mathrm{CB}$ in the south-west and, especially, $\mathrm{MH}$ in the north. The $F_{\mathrm{ST}}$ values between $\mathrm{MH}$ and all other samples clearly indicate strong demographic independence and possibly long-term isolation, in line with the known fragmented nature of whelk populations along the western Irish shelf (BIM 2005). WF and KQ also differ significantly from samples in the southern Irish Sea $\left(F_{\mathrm{ST}}>0.01\right)$, but, interestingly, they also differ from each other, despite being only about $30 \mathrm{~km}$ apart. WF was the only sample coming from a population found inside a tidal inlet, and Weetman et al. (2006) documented that populations from inlets tend to be significantly differentiated from open-shelf populations. Our data for WF and KQ seem to support this pattern, as $\mathrm{KQ}$ appears almost twice as divergent from WF than from the almost 10 -fold more geographically distant CB in the west. This might result from a stepping-stone connectivity model among whelk populations on the open shelf, which does not directly link the more isolated inshore populations. The analysis of additional inshore and offshore samples along the Irish south coast would allow this hypothesis to be tested. It should also be noted that, rather puzzlingly, $\mathrm{KQ}$ appears genetically indistinguishable from the northernmost populations from the Irish Sea (SK, HO and DL), which is difficult to explain, unless some degree of human-mediated translocation is assumed. However, only 26 individuals were screened from $K Q_{i}$ thus, it is wise to interpret this result with some caution. The apparent minor discrepancy between MDS analysis (which places KQ in proximity of SK) 
and BARRIER (which identifies the third discontinuity east of $\mathrm{KQ}$ ) is determined by the geographical constraints implicit in the BARRIER algorithm, which emphasizes the genetic differentiation between WF and $\mathrm{KQ}$, on one side, and the neighbouring localities in the southern Irish Sea (WE, AR, CO) on the other.

Effective population size estimates were high for nearly all samples, suggesting a very large pool of breeders, which might never have experienced the phenomenon of pollution-induced imposex observed in other northern European waters (Nicholson \& Evans 1997, Strand \& Jakobsen 2002). Yet, some evidence of $N_{\mathrm{e}}$ reductions was detected in AR and CB. The former corresponds to the traditional core area for the Irish whelk fishery (Fahy et al. 2000, 2005); thus, it is possible that some patches of this heavily exploited area may be sustained only by a limited number of breeders. On the other hand, CB is located at the westernmost edge of Buccinum undatum's European distribution range; hence, it is not surprising to record a smaller breeding unit in this marginal population.

\section{Discordance between genetic and phenotypic data}

Contrasting patterns garnered using different tools for unravelling spatial population structure is a relatively common finding, and also increasingly documented in marine populations (Abaunza et al. 2008, Sala-Bozano et al. 2009, André et al. 2011, SalaBozano \& Mariani 2011, Yebra et al. 2011). When comparing neutral genetic markers with phenotypic features putatively associated with ecological functions (McKay \& Latta 2002), the objective is to explore in what way and to what extent neutral and adaptive processes differ in shaping the evolutionary trajectories of species.

In common with many long-lived, laboratory-intractable animals, we did not have data on the genetic components of phenotypic variation. Yet, for shell thickness, the critical minimum ratio of $c / h^{2}$ was very low, indicating that only a small fraction of the observed phenotypic variation among populations need have a genetic basis for $Q_{\mathrm{ST}}$ to exceed $F_{\mathrm{ST}}$. Thus, widespread diversifying selection acting on shell thickness seems plausible. Whilst critical $c / h^{2}$ was somewhat higher for RW3, pronounced geographical variation was evident, which clearly differed from the pattern shown by neutral markers. Thus, again, a conclusion of diversifying selection $\left(Q_{\mathrm{ST}}>F_{\mathrm{ST}}\right)$ seems reasonable, albeit perhaps reflecting processes at a larger geographic scale than for shell thickness. For the other components of shape investigated in detail (RW1 and RW2), among-population additive genetic variation would need to be approximately half that found within populations for $Q_{\mathrm{ST}}$ to significantly exceed $F_{\mathrm{ST}}$. Colson et al. (2006) estimated a mean $h^{2}$ of 0.51 for shell-shape components of the dog whelk Nucella lapillus, and CondePadin et al. (2007) documented $h^{2}$ values within the range from 0.35 to 0.7 for shell-shape components in another direct-developing gastropod, Littorina saxatalis. If $h^{2}$ values were of a similar range for Buccinum undatum, the among-population additive genetic proportion of phenotypic variation $(C)$ would need to be substantial ( $\sim 0.15$ to 0.35$)$ for the RW1 and RW2 $Q_{\mathrm{ST}}$ values to exceed $F_{\mathrm{ST}}$. Whether or not this is realistic is unclear, as the influence of phenotypic plasticity may vary greatly among species and across traits. 'Wild' studies, such as the present one, appear not to inflate $Q_{\mathrm{ST}}$ estimates compared to studies based on common garden experiments (Leinonen et al. 2008), suggesting that $c$ may often be quite large. Nevertheless, a conservative application of $P_{\mathrm{ST}}$ to $F_{\mathrm{ST}}$ approaches seems warranted (Brommer 2011) and is likely to prove useful in several contexts whereby conservation and management decisions are needed urgently and the sole application of neutral markers fails to provide the complete picture.

Furthermore, even in the case of an uncertain magnitude of difference between $P_{\mathrm{ST}}$ and $F_{\mathrm{ST}}$, visual (Fig. 6) and statistical (Table 5) aids show that the pattern of pairwise comparisons obtained with microsatellites does not match the patterns obtained with any of the phenotypic descriptors, including RW1 and RW2. Although pairwise estimates of divergence are inherently noisy, such a lack of correlation could indicate that, even for RW1 and RW2, the processes driving neutral divergence are inherently different from those responsible for morphological differentiation in Buccinum undatum.

\section{Ecological relevance of morphological traits}

The present study provides evidence of demographic independence, as well as of ecological adaptation among common whelk populations around Ireland. These results should at least to some extent be incorporated in future management strategies, in order to help in achieving sustainability of what continues to be an economically important fishery (BIM 2005, Fahy 2008). However, it remains difficult to pinpoint the ecological and environmental drivers of phenotypic variation in this species. 
A large body of work documents both inducible and constitutive defences in gastropod molluscs (Hollander et al. 2006, Bourdeau 2011), particularly in response to predators (Edgell \& Neufeld 2008, Auld \& Relyea 2011); however, shell traits have also been shown to be affected by changes in water chemistry (Bibby et al. 2007) and even parasite infection (Thieltges at al. 2009). Thickness, perhaps the most intraspecifically variable of all shell traits, can function as a direct (Brookes \& Rochette 2007) and indirect (Bourdeau 2010) response to 'crushing' predators, such as lobster. Thus, the significantly thicker shells observed in $\mathrm{MH}$ could reflect the selective pressure of lobsters on the North Atlantic coast, where this predator is abundant (BIM 1999), while the thin-shelled whelks in the Irish Sea, as well as their sheer abundance, is in line with the scarcity of lobsters in this area.

The multidimensional descriptors of shell shape obtained through geometric morphometrics are less easy to link to specific ecological processes, but some clues are offered by the pattern identified in the RW3 scores. Tighter siphonal notches and more elongated aperture margins could represent an adaptation against 'handling' clawed predators, such as crabs (Shoup 1968), which are also more abundant in Atlantic areas than in the Irish Sea (where wider and broader notched shells are observed). This would also explain the overall association between RW3 and geographic distance, which, rather than reflecting a demographic or dispersal process, most likely coincides with the fact that the most geographically distant samples overlap with the areas most exposed to clawed predators (BIM 2005, Fahy et al. 2005, Meredith \& Fahy 2005).

It is evident that more targeted experimental investigations will be needed in order to determine the ecological correlates of morphological variation in this and other species and over a range of environmental contexts. Meanwhile, the rapid development of new molecular approaches (Allendorf et al. 2010) promises to offer tools to directly link genomic variation with phenotypic traits, therefore bringing us closer to a full understanding of adaptation in the wild.

Acknowledgements. We thank John Hickey for his help in facilitating sampling, and all the fishermen who keenly provided whelk samples for the study. We are also grateful to Alice Antoniacomi, Jen Coughlan, Carlotta Sacchi, Giorgia Ortolani, Tasman Crowe, Martin Robinson, Jan Drent, for providing technical and intellectual input during the project; to Ed Fahy for the many inspiring discussions on whelks, sea fisheries and sea food; and to 2 anonymous reviewers, who provided constructive criticism on the manuscript. The pre- sent study was supported by Grant No. 05.SM.T1.34 from B.I.M., the Irish Sea Fisheries Board, to S.M. We dedicate this study to the memory of fishermen Thomas Hennessy, Pat Hennessy, Patrick Coady, Billy O'Connor, Andriy Dyrin, Ger Bohan and Tomasz Jagla, who tragically lost their lives at sea in 2007.

\section{LITERATURE CITED}

Abaunza P, Murta AG, Campbell N, Cimmaruta R and others (2008) Stock identity of horse mackerel (Trachurus trachurus) in the Northeast Atlantic and Mediterranean Sea: integrating the results from different stock identification approaches. Fish Res 89:104-113

Allendorf FW, Hohenlohe PA, Luikart G (2010) Genomics and the future of conservation genetics. Nat Rev Genet 11:697-709

André C, Larsson LC, Laikre L, Bekkevold D and others (2011) Detecting population structure in a high geneflow species, Atlantic herring (Clupea harengus): direct, simultaneous evaluation of neutral vs putatively selected loci. Heredity 106:270-280

Auld JR, Relyea RA (2011) Adaptive plasticity in predatorinduced defences in a common freshwater snail: altered selection and mode of predation due to prey phenotype. Evol Ecol 25:189-202

Bibby R, Cleall-Harding P, Rundle S, Widdicombe S, Spicer $\mathrm{J}$ (2007) Ocean acidification disrupts induced defences in the intertidal gastropod Littorina littorea. Biol Lett 3: 699-701

BIM (Bord Iscaigh Mhara) (1999) The Irish inshore fisheries sector: review and recommendations. BIM, Dun Laoghaire. Available at: www.bim.ie (accessed in April 2011)

BIM (Bord Iscaigh Mhara) (2005) Managing Ireland's inshore fisheries. BIM, Dun Laoghaire. Available at: www.bim.ie (accessed in April 2011)

Bonnet E, van de Peer Y (2002) zt: a software tool for simple and partial Mantel tests. J Stat Softw 7:1-12

Bookstein FL (1991) Morphometric tools for landmark data: geometry and biology. Cambridge University Press, Cambridge

Bourdeau PE (2010) An inducible morphological defence is a passive by-product of behaviour in a marine snail. Proc Biol Sci 277:455-462

> Bourdeau PE (2011) Constitutive and inducible defensive traits in co-occurring marine snails distributed across a vertical rocky intertidal gradient. Funct Ecol 25:177-185

Brommer JE (2011) Whither $P_{\mathrm{ST}}$ ? The approximation of $Q_{\mathrm{ST}}$ by $P_{\mathrm{ST}}$ in evolutionary and conservation biology. J Evol Biol 24:1160-1168

Brookes JI, Rochette R (2007) Mechanism of a plastic phenotypic response: predator-induced shell thickening in the intertidal gastropod Littorina obtusata. J Evol Biol 20: 1015-1027

> Brookfield JFI (1996) A simple new method for estimating null allele frequency from heterozygote deficiency. Mol Ecol 5:453-455

> Brown J, Carrillo L, Fernand L, Horsburgh KJ, Hill AE, Young EF, Medler KJ (2003) Observations of the physical structure and seasonal jet-like circulation of the Celtic Sea and St George's Channel of the Irish Sea. Cont Shelf Res 23:533-561

> Colson I, Hughes RN (2004) Rapid recovery of genetic diversity of dogwhelk (Nucella lapillus L.) populations after local extinction and recolonization contradicts predic- 
tions from life-history characteristics. Mol Ecol 13: 2223-2233

- Colson I, Guerra-Valela J, Hughes RN, Rolán-Alvarez E (2006) Using molecular and quantitative variation for assessing genetic impacts on Nucella lapillus populations after local extinction and recolonization. Integr Zool 1:104-107

- Conde-Padin P, Carvajal-Rodriguez A, Carballo M, Caballero A, Rolan-Alvarez E (2007) Genetic variation for shell traits in a direct-developing marine snail involved in a putative sympatric ecological speciation process. Evol Ecol 21:635-650

Edelaar P, Björklund M (2011) If $F_{\mathrm{ST}}$ does not measure neutral genetic differentiation, then comparing it with $Q_{\mathrm{ST}}$ is misleading. Or is it? Mol Ecol 20:1805-1812

Edgell TC, Neufeld CJ (2008) Experimental evidence for latent developmental plasticity: intertidal whelks respond to a native but not an introduced predator. Biol Lett 4:385-387

Excoffier L, Laval G, Schneider S (2006) Arlequin Ver 3.1: an integrated software package for population genetics data analysis. Available at: http://cmpg.unibe.ch/ software/arlequin3

Fahy E (2008) Performance of an inshore fishery in the absence of regulatory enforcement. Mar Policy 32: 1037-1042

Fahy E, Masterson E, Swords D, Forrest N (2000) A second assessment of the whelk fishery Buccinum undatum in the southwest Irish Sea with particular reference to its history of management by size limit. Irish Fisheries Investigations 6. The Marine Institute, Dublin

Fahy E, O'Toole M, Stokes D, Gallagher M (2002) Appraisal of the whelk (Buccinum undatum) fishery on a part of the Codling Bank following aggregate extraction for beach restoration at Bray, Co. Wicklow. Marine Institute Fishery Leaflet 11 . The Marine Institute, Dublin

Fahy E, Carroll J, O'Toole M, Barry C, Hother-Parkes L (2005) Fishery-associated changes in the whelk Buccinum undatum stock in the southwest Irish Sea, 1995-2003. Irish Fisheries Investigations 15. The Marine Institute, Dublin

Frankham R (2010) Challenges and opportunities of genetic approaches to biological conservation. Biol Conserv 143: 1919-1927

Goudet J (1995) FSTAT (Version 1.2): a computer program to calculate F-statistics. J Hered 86:485-486

Hammer Ø, Harper DAT, Ryan PD (2001) PAST: paleontological statistics software package for education and data analysis. Palaeontol Electronica 4. Available at: http:// palaeo-electronica.org/2001_1/past/issue1_01.htm

Hancock DA (1963) Marking experiments with the commercial whelk (Buccinum undatum). Int Comm NW Atl Fish Spec Publ 4:176-187

Hauser L, Carvalho G (2008) Paradigm shifts in marine fisheries genetics: ugly hypotheses slain by beautiful facts. Fish Fish 9:333-362

Hedrick PW (2005) A standardized genetic differentiation measure. Evolution 59:1633-1638

Hilborn R, Quinn TP, Schindler DE, Rogers DE (2003) Biocomplexity and fisheries sustainability. Proc Natl Acad Sci USA 100:6564-6568

Himmelman JH, Hamel JR (1993) Diet, behaviour and reproduction of the whelk Buccinum undatum in the northern Gulf of St. Lawrence, eastern Canada. Mar Biol 116:423-430
Hohenlohe PA, Bassham S, Etter PD, Stiffler N, Johnson EA, Cresko WA (2010) Population genomics of parallel adaptation in threespine stickleback using sequenced RAD tags. PLoS Genet 6:e1000862 doi: 10.1371/journa.pgen. 1000862

Hollander J, Butlin RK (2010) The adaptive value of phenotypic plasticity in two ecotypes of a marine gastropod. BMC Evol Biol 10:333

Hollander J, Collyer ML, Adams DC, Johannesson K (2006) Phenotypic plasticity in two marine snails: constraints superseding life history. J Evol Biol 19:1861-1872

Hood GM (2010) PopTools Version 3.2.3. Available at: www. poptools.org

Horsburgh KJ, Hill AE, Brown J, Fernand L, Garvine RW, Angelico MMP (2000) Seasonal evolution of the cold pool gyre in the western Irish Sea. Prog Oceanogr 46:1-58

$>$ Jost L (2008) $G_{\mathrm{ST}}$ and its relatives do not measure differentiation. Mol Ecol 17:4015-4026

> Leinonen T, O'Hara RB, Cano JM, Merila J (2008) Comparative studies of quantitative trait and neutral marker divergence: a meta-analysis. J Evol Biol 21:1-17

> Manni F, Guérard E, Heyer E (2004) Geographic patterns of (genetic, morphologic, linguistic) variation: how barriers can be detected by 'Monmonier's algorithm'. Hum Biol 76:173-190

Mantel N (1967) The detection of disease clustering and a generalized regression approach. Cancer Res 27: 209-220

McKay JK, Latta RG (2002) Adaptive population divergence: markers, QTL and traits. Trends Ecol Evol 17: 285-291

Meirmans PG, Hedrick PW (2011) Assessing population structure: $F_{\mathrm{ST}}$ and related measures. Mol Ecol Resour 11: 5-18

Meredith D, Fahy E (2005) The status of the inshore component of the northern brown crab Cancer pagurus fishery, assessed from a time series of LPUE constructed from historical sources. Irish Fisheries Bulletin 23. Marine Institute, Galway

Merilä J (1997) Quantitative trait and allozyme divergence in the greenfinch (Carduelis chloris, Aves: Fringillidae). Biol J Linn Soc Lond 61:243-266

> Merilä J, Crnokrak P (2001) Comparison of genetic differentiation at marker loci and quantitative traits. J Evol Biol 14:892-903

> Merilä J, Sheldon B (1999) Genetic architecture of fitness and non-fitness traits: empirical patterns and development of ideas. Heredity 83:103-109

Miller KM, Li S, Kaukinen KH, Ginther N and others (2011) Genomic signatures predict migration and spawning failure in wild Canadian salmon. Science 331:214-217

Nei M (1987) Molecular evolutionary genetics. Columbia University Press, New York, NY

Nicholson GJ, Evans SM (1997) Anthropogenic impacts on the stocks of the common whelk Buccinum undatum (L.). Mar Environ Res 44:305-314

Pigliucci M (2005) Evolution of phenotypic plasticity: Where are we going now? Trends Ecol Evol 20:481-486

Räsänen K, Hendry AP (2008) Disentangling interactions between adaptive divergence and gene flow when ecology drives diversification. Ecol Lett 11:624-636

Raymond M, Rousset F (1995) GENEPOP (Version 1.2): a population genetics software for exact tests and ecumenicism. J Hered 86:248-249

Rohlf FJ (2004) TpsDig, digitize landmarks and outlines, 
Version 2.0. Department of Ecology and Evolution, New York State University, Stony Brook, NY

Rohlf FJ, Slice DE (1990) Extensions of the Procrustes method for the optimal superimposition of landmarks. Syst Zool 39:40-59

Rolán-Alvarez E, Carballo M, Galindo J, Moran P and others (2004) Nonallopatric and parallel origin of local reproductive barriers between two snail ecotypes. Mol Ecol 13:3415-3424

Ryman N, Leimar O (2009) $G_{\mathrm{ST}}$ is still a useful measure of genetic differentiation - a comment on Jost's D. Mol Ecol 18:2084-2087

Saether SA, Fiske P, Kålås JA, Kuresoo A and others (2007) Inferring local adaptation from $Q_{\mathrm{ST}}-F_{\mathrm{ST}}$ comparisons: neutral genetic and quantitative trait variation in European populations of great snipe. J Evol Biol 20: 1563-1576

Sala-Bozano M, Mariani S (2011) Life history variation in a marine teleost across a heterogeneous seascape. Estuar Coast Shelf Sci 92:555-563

Sala-Bozano M, Ketmaier V, Mariani S (2009) Contrasting signals from multiple markers illuminate population connectivity in a marine fish. Mol Ecol 18:4811-4826

Shoup JB (1968) Shell opening by crabs of the genus Calappa. Science 160:887-888

Slatkin M (1993) Isolation by distance in equilibrium and nonequilibrium populations. Evolution 47:264-279

Spitze K (1993) Population structure in Daphnia obtusa: quantitative genetic and allozymic variation. Genetics 135:367-374

Strand J, Jakobsen JA (2002) Imposex in two sublittoral neogastropods from the Kattegat and Skagerrak: the common whelk Buccinum undatum and the red whelk Neptunea antiqua. Mar Ecol Prog Ser 244:171-177
Thieltges DW, Saldanha I, Leung TLF, Poulin R (2009) Contribution of parasites to intra- and inter-site variation in shell morphology of a marine gastropod. J Mar Biol Assoc UK 89:563-568

$>$ van Oosterhout C, Hutchinson WF, Wills DPM, Shipley P (2004) MiCRO-CHECKER: software for identifying and correcting genotyping errors in microsatellite data. Mol Ecol Notes 4:535-538

> Vermeij GJ (2002) Characters in context: molluscan shells and the forces that mold them. Paleobiology 28:41-54

Waples RS, Do C (2008) LDNE: a program for estimating effective population size from data on linkage disequilibrium. Mol Ecol Resour 8:753-756

Waples RS, Punt AE, Cope JM (2008) Integrating genetic data into management of marine resources: How can we do it better? Fish Fish 9:423-449

> Weetman D, Hauser L, Shaw PW, Bayes MK (2005) Microsatellite markers for the whelk Buccinum undatum. Mol Ecol Notes 5:361-362

> Weetman D, Hauser L, Bayes MK, Ellis JR, Shaw PW (2006) Genetic population structure across a range of geographic scales in the commercially exploited marine gastropod Buccinum undatum. Mar Ecol Prog Ser 317: 157-169

- Weir BS, Cockerham CC (1984) Estimating F-statistics for the analysis of population structure. Evolution 38:1358-1370

$>$ Whitlock MC (2008) Evolutionary inference from $Q_{\mathrm{ST}}$. Mol Ecol 17:1885-1896

Whitlock MC (2011) $G_{\mathrm{ST}}^{\prime}$ and $D$ do not replace $F_{\mathrm{ST}}$. Mol Ecol 20:1083-1091

Yebra L, Bonnet D, Harris RP, Lindeque P, Peijnenburg KTCA (2011) Barriers in the pelagic: population structuring of Calanus helgolandicus and $C$. euxinus in European waters. Mar Ecol Prog Ser 428:135-149 
Appendix 1. Analytical steps to ascertain whether the association between shell length and thickness varied among locations.

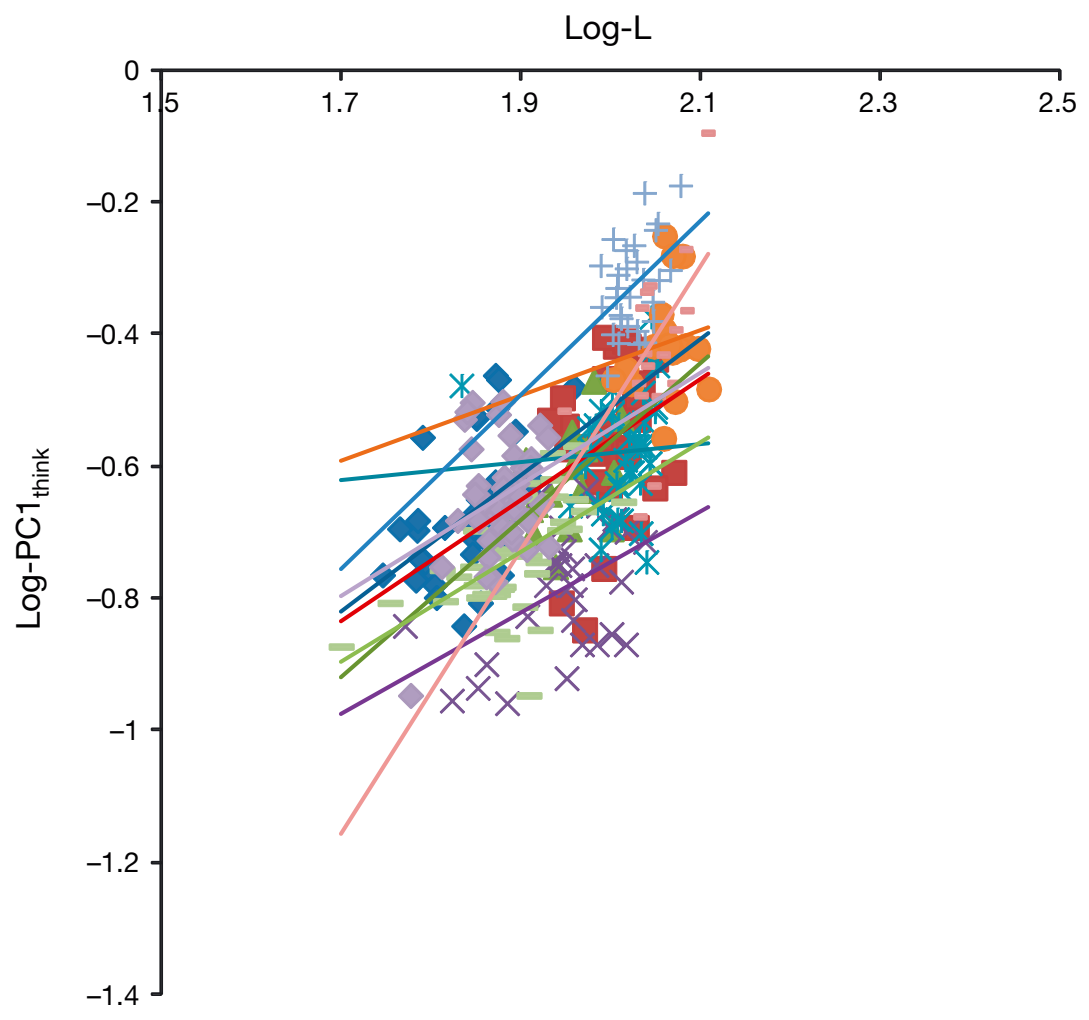

Fig. A1. Buccinum undatum. Log-transformed Principal Component 1 (LOGPC1) scores of shell thickness plotted against LogLength (LOGL) for the common whelk from 10 localities around Ireland

Table A1. Buccinum undatum. General linear model results testing for potential interaction between LogLength (LOGL) and population of origin (POP). Both LOGL and POP remain significant after the removal of the non-significant interaction term. Dependent variable: Log Principal Component 1

\begin{tabular}{|lccccc|}
\hline Source & $\begin{array}{c}\text { Type III } \\
\text { sum of squares }\end{array}$ & df & $\begin{array}{c}\text { Mean } \\
\text { square }\end{array}$ & $F$ & Significance \\
\hline Corrected model & $5.934^{\mathrm{a}}$ & 19 & 0.312 & 43.964 & 0.000 \\
Intercept & 0.431 & 1 & 0.431 & 60.739 & 0.000 \\
LOGL & 0.263 & 1 & 0.263 & 37.055 & 0.000 \\
POP & 0.066 & 9 & 0.007 & 1.029 & 0.417 \\
POP $\times$ LOGL & 0.071 & 9 & 0.008 & 1.116 & 0.351 \\
Error & 2.046 & 288 & 0.007 & & \\
Total & 118.695 & 308 & & & \\
Corrected total & 7.980 & 307 & & & \\
${ }^{2} \mathrm{R}^{2}=0.744$ (adjusted $\mathrm{R}^{2}=0.727$ ) & & & & & \\
\hline
\end{tabular}

Editorial responsibility: Roger Hughes, Bangor, UK
Submitted: July 26, 2011; Accepted: November 14, 2011 Proofs received from author(s): January 26, 2012 